\section{Animal Systematics}

Principles of Systematic Zoology. By Ernst Mayr. Pp. xi +428. (McGrawHill: New York and Maidenhead, 1969.) $£ 6.00$.

For many years, Ernst Mayr has been a leading American publicist in the struggle to maintain, in defiance of the zeitgeist, the central importance of systematics in the science of zoology. With the issue of the fight to which Mayr has devoted so much of his time and formidable energy still undecided either in the USA or in the world at large, many of us regret the lack of a champion of his stature to wage a similar battle in Britain. The present book, designed primarily as a practical handbook for those already committed to the pursuit of systematics, is fitted also to recruit to the side of Mayr's angels any uncommitted zoologist with an interest in the diversity of animals.

The book is in essence a rewritten and updated version of the well-known Methods and Principles of Systematic Zoology of Mayr, Linsley and Usinger (1953). That work has been out of print for some time and, respected as it was among professional systematists, it suffered from a rather severely pedantic style of presentation. The new book is far easier to read and, while sacrificing none of the valuable scientific content of its predecessor, incorporates much new material on nomenclature, numerical taxonomy, biochemical systematics and so forth.

In relation to recent disputes about the proper basis of classification, Mayr adopts a more or less pragmatic approach. While admitting the usefulness in some circumstances of the techniques of the numerical taxonomists, he rejects their fundamentalist claims (treating them as a variant of philosophical "nominalism"); similarly, he regards an understanding of evolutionary relationships as essential to the construction of a really natural classification, but holds up to ridicule the effects of a general application of Hennig's phylogenetic principles (known as "cladism" in America).

As a practising systematist, Mayr works with birds, and the characteristic bias of 20th century avian systematics --an overwhelming preoccupation with species and subspecies as against higher classification-is perceptible in his book The two chapters on species and infraspecific classification are particularly good, whereas classification above the species level is rather summarily disposed of in only six pages. $\mathrm{He}$ states indeed that "the time has not yet come to present a well-balanced methodology of macrotaxonomy".

On the actual procedures of a modern museum systematist Mayr writes well and with considerable authority. $\mathrm{He}$ is rather cautiously optimistic about the future possibilities of protein and DNA studies and of serotaxonomy, which are somewhat briefly considered in the book, but is fully alive to the importance of behaviour as a factor in animal evolution and hence in classification. Fossils, and the special problems involved in classifying them, are not specifically considered, no doubt in deference to the superior authority in this field of G. G. Simpson and A. S. Romer. The palaeontologist will probably continue to refer to Simpson's Principles of Animal Taxonomy (1961).

Mayr is an eminent member of the International Commission on Zoological Nomenclature, so it is not surprising to find in his book the complete English language text of the latest (1961) international code of nomenclature, together with an unusually extensive and authoritative exposition of its implications. Prospective purchasers of the official text of the code might get better value for their money by buying Mayr's book instead. It is understandable that he, unlike some other recent writers on the subject, refrains from radical criticisms of the present code.

In sum, this work offers perhaps the most representative and authoritative of all the accounts yet published of the principles and practices of present-day systematic zoologists, and for this reason may be valued by historians of science in future centuries. Mayr is not concerned to advocate views which are peculiarly his own, but writes responsibly as the spokesman of a rather solid consensus. Those who look for radically new ideas or approaches will not find them in this book, but should be warned that books in which such ideas are put forward generally fall a long way short of this one in other respects.

\section{R. A. Crowson}

\section{Light, Time and Animals}

Animal Photoperiodism. By Brian Lofts. (The Institute of Biology's Studies in Biology, No. 25.) Pp. ${ }^{\circ} 62$. (Arnold: London, November 1970.) $£ 1.00$ boards ; $£ 0.60$ paper.

THE preface to this booklet states that it is an introduction to the extensive literature on photoperiodism aimed at students at school or in their first year at university. It certainly achieves this aim, and is an admirable attempt to bring together information on seasonal and daily cycles in all the animal groups which have been used as experimental material, although it naturally stresses the author's own interests in avian photoperiodism. This accent on birds makes the chapter on invertebrate (meaning arthropod) photoperiodism seem a bit thin, especially as the preface also states that suggestions are made for appropriate practical work, and insects present very favourable experimental material in terms of speed of reaction, size and expendability. In the chapter on daylength measurement more could have been said about the number of light:dark cycles required to produce the photoperiodic response, and perhaps something on the location of the clock, its spectral sensitivity, and the endocrine mechanisms linked to it. Results from "night interruption" experiments with Pieris brassicae showing one peak of diapause inhibition are the result of incomplete "scanning" of the night by light pulses (Fig. 6-4), and other, two oscillator, hypotheses have been proposed to account for time measurement in the insects.

D. S. SAUNDERS

\section{From the Camargue}

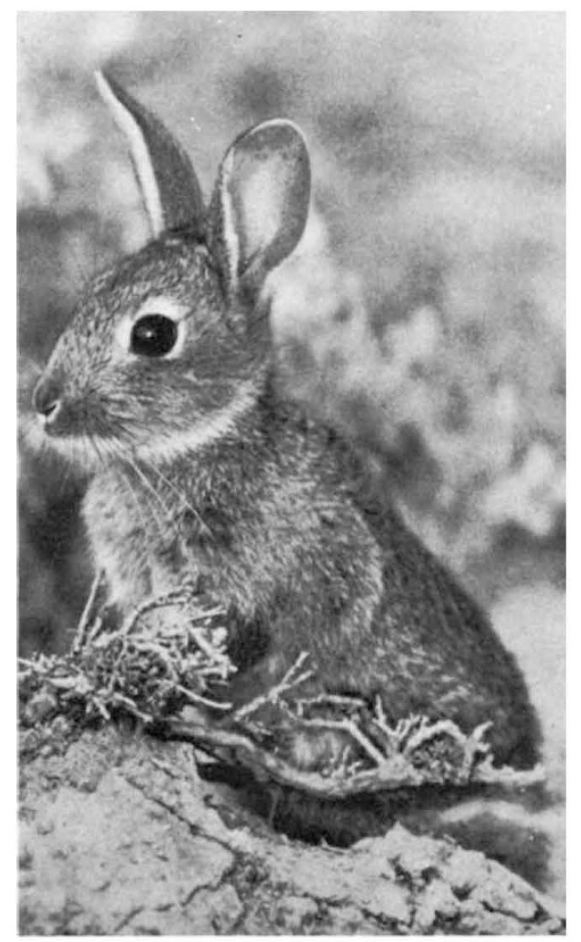

This young rabbit (Oryctolagus cuniculus) is an inhabitant of the Camargue, that triangle of land bounded by the two arms of the Rhône and by the Mediterranean coast which forms the area of the Rhône estuary. Myxomatosis decimated the rabbit population of the Camargue in 1953, but more recently their numbers have recovered. This photograph is one of a splendid series both in colour and in black-and-white which illustrate Comorgue by Karl Weber and Lukas Hoffman, the result of a four year ecological study of the region (Harrap: London, March 1971, 16.30). 